\title{
Biruk, C. (2018). Culture and politics in an African research world. Durham: Duke University Press. 277 p.
}

\author{
FELIPE ANTÔNIO HONORATO
}

UNIVERSIDADE DE SÃO PAULO (USP), SÃO PAULO/SP, BRASIL

HTTPS://ORCID.ORG/OO00-0003-3732-6533

Cooking data: Culture and politics in an African research world, primeiro livro de Crystal Biruk, professora associada de antropologia da McMaster University, no Canadá, foi construído para ser uma etnografia da produção de dados quantitativos. São perguntas centrais e que nortearam a composição do livro: como unidades cruas de informação adquirem valor estatístico e embasam políticas públicas e intervenções? De que forma as dinâmicas e práticas de campo da cultura de aplicação de questionários mediam a produção de números? Como dados quantitativos sobre saúde e seus mundos sociais são co-produzidos e com quais consequências para as economias locais, formulação de conhecimento e experiência vivida?

O termo cooking data, presente no título do livro de Biruk, tem origem em uma obra de Lévi-Strauss, The raw and the cooked, de 1969, e possui dois sentidos: fabricar dados ou processar dados crus, para que eles virem dados de alta qualidade. Uma única expressão, que carrega em si, portanto, dois sentidos antagônicos que marcam a tônica da produção de dados em campo: criar uma padronização que evite a produção de dados de baixa qualidade - o que inclui dados inventados - e que leve à produção de dados de alta qualidade, que, à frente, servirão para embasar estatísticas acuradas e políticas públicas bem planejadas.

$\mathrm{Na}$ introdução da obra, a autora explica que, para elaborar o livro, ela acompanhou, entre $2005 \mathrm{e}$ 2007 - 2008, o trabalho de campo feito, principalmente, por dois projetos: o LSAM e o MAYP. Ambos os projetos coletaram dados de pesquisa e testes de HIV, a nível doméstico, de moradores do Malawi, especialmente em áreas rurais. Enquanto os dados do LSAM rastrearam as condições demográficas, socioeconômicas e as condições de saúde no Malawi rural, os dados do MAYP rastrearam uma amostra de jovens casais em sua transição ao matrimônio.

A antropóloga detalha que sua observação participante pode ser dividida, basicamente, em três etapas. Inicialmente, um período de 3 meses no LSAM como assistente de pesquisa no ano de 2005, onde sua função era colaborar com as tarefas diárias de pesquisa. Depois, entre 2007 e 2008, ela trabalhou para diferentes projetos, ajudando em todas as etapas das investigações: checagem e aplicação de 
questionários, logística, catalogação de dados, etc. Por último, em 2008, após o término dos projetos de pesquisa, Crystal Biruk ainda ficou um mês nas áreas onde se encontravam as amostras do LSAM e do MAYP, conversando com entrevistados pelos projetos junto com um assistente de pesquisa.

Formatar o design de uma pesquisa é uma negociação que envolve diversos fatores: recursos financeiros, a capacidade de implementação de uma pesquisa, etc. Em "The office in the field: building survey infrastructure", primeiro dos cinco capítulos que compõem o livro, a pesquisadora reflete justamente sobre isso: faz uma extensa análise etnográfica das questões, tensões e problemáticas sociais envolvidas na preparação de uma pesquisa de campo, que, nos casos estudados por Crystal Biruk, constituíram-se na aplicação de questionários em zonas rurais do Malawi. A autora aborda pontos como a complexidade envolvida no processo de tradução de questionários de línguas estrangeiras, a exemplo do inglês, para línguas locais do país africano: a tradução de pesquisa não é apenas preocupada com a dimensão linguística, mas também em saber se as traduções fazem sentido no âmbito cultural em que serão utilizadas - não se pode, por exemplo, usar uma situação cotidiana para ilustrar uma questão que não faça sentido no contexto para o qual se está traduzindo. Uma tradução correta e acurada de um questionário é tão importante para uma pesquisa quanto entrevistadores bem treinados, que façam as perguntas exatamente como ensaiado ou escrito.

Neste mesmo capítulo a autora trabalha com as diferenças entre o Norte e o Sul global refletidas no ambiente de pesquisa. De acordo com ela, há um reconhecimento da desigualdade das cooperações de pesquisa entre estas duas distintas regiões econômicas do globo; o elo de ligação entre pesquisadores das duas áreas é o dinheiro, proveniente do financiamento para pesquisas que verte do norte em direção ao sul. Isto acaba por formar uma hierarquia no trabalho de campo: o nível mais baixo é ocupado pelos coletores de dados que vão para o campo, vistos como mão de obra não qualificada e facilmente substituível; o nível mais alto é ocupado por pesquisadores do primeiro mundo, que comandam pesquisas à distância; entre estes dois níveis estão os pesquisadores locais, do terceiro mundo, que oferecem expertise local e coordenam o trabalho feito pelos coletores de dados.

O segundo capítulo, "Living project to project: brokering local knowledge in the field", vai tratar justamente do papel da mão de obra local no escopo destas investigações científicas internacionais desenvolvidas no Malawi: pode parecer que os pesquisadores do terceiro mundo não são protagonistas nelas, mas a verdade é que eles dominam os processos logísticos e de pesquisa em campo. Formou-se, no Malawi, um "mercado" de venda do conhecimento: acadêmicos africanos, muitas vezes, dependem destas atividades de cooperação para complementar os baixos salários oferecidos pelas universidades no continente; eles, que em várias ocasiões participam de múltiplos projetos ao mesmo tempo, deixando um pouco de lado suas áreas de expertise a favor dos ganhos, oferecem, como grande diferencial a parceiros estrangeiros, que são, principalmente, universidades estadunidenses e europeias, o seu conhecimento da realidade local, uma moeda de troca muito valiosa nestes contextos.

Neste segundo capítulo, Biruk também discute sobre o trabalho dos coletores de dados no campo, fazendo uma etnografia destes. A autora tenta subverter a ideia de que eles são trabalhadores de baixa qualificação, como se acredita: ela mostra como este tipo de função, apesar de temporária e apresentar vínculos empregatícios precários, pode significar mobilidade social para algumas pessoas no 
Malawi; a oportunidade oferecida pela participação nessas pesquisas para locais é boa, se comparada à realidade do país africano. Fica claro, ao longo do capítulo, que estes pesquisadores de campo prezam muito por manter uma boa relação com seus empregadores, bem como pela qualidade dos dados que coletam, afinal a confiança dos pesquisadores internacionais é o que vai lhes garantir, futuramente, novos trabalhos.

O terceiro capítulo, batizado de "Clean data, messy gifts: soap-for-information transactions in the field", traz uma discussão sobre a ética e a simbologia de se dar sabão em troca da participação de respondentes nas aplicações de questionários em campo. Ele é enxergado, do ponto de vista prático, como uma recompensa ideal, pois é fácil e compacto para ser carregado pelos pesquisadores em campo. Já no ponto de vista ético, no entanto, não é unanimidade: se, por um lado, é um produto de moderado valor econômico, não se configurando, então, como um possível incentivo à participação de ninguém nas pesquisas, o sabão, por outro lado, é condenável, porque, na melhor das hipóteses, ninguém deveria receber nada em troca por participar de uma pesquisa - os respondentes deveriam participar apenas pela vontade de colaborar.

Crystal Biruk aborda toda a expectativa que acabou sendo criada no Malawi, por parte de quem iria responder os questionários, quanto ao ganho do sabão, implicando em situações como, por exemplo, pessoas se passando por outras para poderem ter acesso à recompensa. Para além das questões éticas e práticas, há também, como já anunciado, o problema da simbologia que o sabão carrega consigo no país africano: o produto foi um sinônimo de saúde e de uma modernidade racializada durante o período colonial.

Durante o decorrer de todo o livro, a autora destaca a presença, no ambiente de pesquisa, de uma falsa oposição entre o campo (que seria um lugar bagunçado e onde os números são pessoas, tomam vida) e o escritório (onde o trabalho de processamento dos dados é feito, que seria limpo, organizado, e onde os entrevistados no campo viram números, cifras). É sobre o desafio de colher dados confiáveis e padronizados - clean data - em um contexto supostamente bagunçado, onde os coletores de dados têm de conviver com situações inusitadas, e, muitas vezes, com o improviso, que o quarto capítulo, "Materializing clean data in the field", trata.

"When number travel: the politics of making evidence-based policy" finaliza a obra. Nele, Crystal Biruk questiona o paradigma que se vive atualmente das políticas públicas baseadas em evidências, contando casos acontecidos no Malawi em que conviç̧ões pessoais de pesquisadores e o senso comum se sobrepuseram a dados e evidências científicas. Tais situações levam Biruk a questionar o fato de que mesmo a padronização sendo uma obsessão de pesquisadores que coordenam pesquisas de campo, para que dados não sejam fabricados, de certa forma eles ainda podem acabar sendo inventados, na última ponta do processo.

Cooking data: Culture and politics in an African research world constitui-se, então, como um livro de grande relevância para todos que queiram ter uma ideia detalhada de como funcionam os processos aplicação de questionários e produção de dados quantitativos na África, ainda que o livro trate especificamente do contexto do Malawi. A etnografia realizada por Biruk também é importante para de- 
monstrar que dados, números, não são "frios": eles, para serem produzidos, envolvem conflitos sociais, conflitos éticos, pessoas, entre outros fatores que se imbricam em uma complicada relação.

Felipe Antônio Honorato é doutorando em Mudança social e participação politica pela Escola de Artes, Ciências e Humanidades da Universidade de São Paulo (EACH-USP) e professor da Faculdade IESCAMP.

RECEBIDO: $31 / 01 / 2021$

ACEITO: 23/04/2021 